\title{
Cómo los visitantes y sus percepciones de los paisajes sonoros pueden mejorar la gestión colaborativa de las áreas protegidas $^{1}$
}

\section{How visitors and their perceptions of soundscapes can improve collaborative management of protected areas}

\author{
Trace Gale ${ }^{2}$ (), Andrea Ednie ${ }^{3}$, Andrés Adiego 4 (1) \\ y Karen Beeftink ${ }^{5}$
}

\begin{abstract}
RESUMEN
Este estudio exploró las percepciones de los paisajes sonoros de la RNC (Reserva Nacional Coyhaique). Encuestas con visitantes $(\mathrm{N}=899)$, incluyeron datos demográficos y un ejercicio de audición del sonido ambiente. Los resultados demostraron interés y afinidad por el sonido como parte de la experiencia de recreación/turismo, con respuestas generalmente positivas para la mayoría de las diez categorías codificadas (Viento, Pájaros, Insectos, Bosque, Agua, Voces, Gente Pasando, Sonidos Personales, Máquinas, Aviones/ Ciudad). Surgieron similitudes y diferencias entre tres grupos de visitantes (lugareños, turistas nacionales, turistas extranjeros), con respecto a la forma en que experimentaron los sonidos. La discusión se centró en: cómo los resultados pueden informar una mejor gestión en la RNC; la forma en que los paisajes sonoros pueden ser utilizados para aumentar la comprensión y el apoyo a sus mandatos; y en posibles iniciativas para fomentar la participación y la gobernanza ciudadana de las Áreas Silvestres Protegidas de Chile.
\end{abstract}

Palabras clave: Paisaje sonoro, área protegida, gobernanza ciudadana, grupos de visitantes, percepciones.

\begin{abstract}
This study explored perceptions of the soundscapes of the CNR (Coyhaique National Reserve). Visitor surveys $(\mathrm{N}=899)$, included demographic data and an exercise in listening to ambient sound. Results showed interest and affinity for sound as part of the recreation/ tourism experience, with generally positive responses for most of the ten coded categories (Wind, Birds, Insects, Forest, Water, Voices, Passersby, Personal Sounds, Machines, Airplanes/City). Similarities and differences emerged between three groups of visitors (locals, national tourists, foreign tourists), with respect to the ways they experienced the sounds. The discussion focused on: how the results can inform better management in
\end{abstract}

Esta investigación fue apoyada por la Agencia Nacional de Investigación y Desarrollo (ANID), en el marco del Programa Regional R17A10002 de la ANID; y el proyecto R2OFOOO2 del CIEP

Centro de Investigación en Ecosistemas de la Patagonia (CIEP), Coyhaique, Chile. Correo electrónico: tracegale@ciep.cl

University of Wisconsin - Whitewater, Estados Unidos. Correo electrónico: edniea@uww.edu

Centro de Investigación en Ecosistemas de la Patagonia (CIEP), Coyhaique, Chile; Universidad de Zaragoza, Departamento de Geografía y Ordenación del Territorio, España. Correo electrónico: andres.adiego@ciep.cl

University of Maine at Machias, Estados Unidos. Correo electrónico: karen.beeftink@maine.edu 
the RNC; how soundscapes can be used to increase understanding and support for RNC mandates; and possible initiatives to encourage citizen participation and governance of Chile's Natural Protected Areas.

Keywords: Soundscape, protected area, citizen governance, visitor groups, perceptions.

En términos generales, la función de la gobernanza de una institución o empresa radica en identificar quién decide cuáles son los objetivos, qué hacer para alcanzarlos y con qué medios; cómo se toman esas decisiones; quién tiene el poder, la autoridad y la responsabilidad y quién es (o debería ser) responsable (Borrini-Feyerabend \& Hill, 2015). En el caso de las APs (áreas protegidas), la UICN (Unión Internacional para la Conservación de la Naturaleza) identifica cuatro tipos de gobernanza: Gobernanza por el Estado, Gobernanza compartida, Gobernanza privada y Gobernanza por pueblos indígenas y comunidad local (Worboys \& Trzyna, 2015). Es probable que el levantamiento social que se produjo en Chile durante los últimos meses de 2019 refuerce una serie de prioridades y acciones estratégicas ya en curso para los Parques y Reservas Nacionales y los Monumentos Naturales de Chile, dando lugar a enfoques más holísticos, equitativos e inclusivos en su gobernanza, que extenderán su relevancia a un segmento más amplio de ciudadanos y visitantes (Ladrón de Guevara, 2014; Petit et al., 2018; Subsecretaría de Turismo, 2017). Muchos académicos creen que el éxito futuro de las APs depende en gran medida de su capacidad para reducir los conflictos sobre la conservación y conseguir un mayor consenso entre los grupos de usuarios con valores y prioridades extremadamente diferentes, con el fin de desarrollar enfoques de cogestión y sistemas de gobernanza que recojan diferentes puntos de vista (Fedreheim \& Blanco, 2017; Hamilton \& Jepson, 2017; Sandström et al., 2014). Así, los administradores de las APs deben estar bien preparados para comprender las percepciones y preferencias locales, y para identificar las diferencias importantes entre sus constituyentes (Pietilä, 2017; Soliku \& Schraml, 2018; Whiting et al., 2017). Para gobernar y gestionar con la participación de los ciudadanos, los administradores de las APs y sus respectivos organismos deben comprender lo que la gente espera cuando visita un AP (Hall et al., 2010; Hvenegaard, 2017).

Por otro lado, los actores locales tendrán que desarrollar una comprensión de los mandatos, los objetivos y otros conceptos técnicos de las APs, necesarios para la adopción de decisiones que equilibren eficazmente los objetivos y valores en pugna que suelen surgir (Hillier, 2018; Mees et al., 2017). En particular, deberán comprender y valorar las diferencias técnicas entre las categorías de APs, para contribuir significativamente a su gobernanza y gestión en relación con la protección de la biodiversidad y la provisión de experiencias de calidad para los visitantes, relacionadas con la educación ambiental, la recreación y el turismo. Esto es especialmente relevante para las regiones patagónicas de Chile, Aysén y Magallanes, donde se encuentra aproximadamente el 85\% de la superficie de las APs del país (Ministerio del Medio Ambiente, 2011). Estas dos regiones tienen más de la mitad de sus respectivos territorios bajo protección y dependen cada vez más de las APs como escenario en el que se desarrolla el sector turístico basado en la naturaleza. Por lo tanto, la preparación de los habitantes locales para contribuir de manera significativa a la gobernanza de las APs y al diseño y gestión de experiencias de calidad para los visitantes, debe ser una prioridad para estas regiones en los próximos años.

En otras partes del mundo, la documentación y el mapeo de los paisajes sonoros, la investigación sobre la percepción y las prácticas de monitoreo, han surgido como herramientas poderosas 
en el diseño, la planificación y la gestión de los espacios públicos, incluidas las APs naturales (Francis et al., 2017; Otondo, 2018). Un paisaje sonoro engloba los sonidos, o la energía sónica, producidos por lugares o paisajes específicos (Farina, 2014; Miller, 2013). Hasta la fecha, las investigaciones sobre el paisaje sonoro en Chile han aportado valiosas contribuciones en Santiago y Valdivia; sin embargo, se han centrado casi exclusivamente en entornos urbanos y, en menor medida, en sus espacios verdes (Otondo, 2018).

Este artículo amplía la investigación del paisaje sonoro y sus potenciales contribuciones a las APs naturales de Chile. El estudio, que tuvo lugar en la RNC (Reserva Nacional Coyhaique), relaciona la variable lugar de residencia con los sonidos producidos en un espacio determinado (paisaje sonoro), explorando la forma en que los visitantes locales, nacionales y extranjeros percibieron los sonidos naturales (de origen biológico o geofísico) y los antrópicos (producidos o modificados por el ser humano) durante sus experiencias. La discusión se centra en la interpretación de los resultados para ayudar a fundamentar posibles estrategias para una gestión y gobernanza ciudadana eficaz, una mejor calidad de las experiencias de los visitantes y formular normas y estándares basados en el lugar.

\section{Objetivos del estudio y preguntas de investigación}

El primer objetivo del estudio fue comprender cómo perciben y experimentan los sonidos los diferentes grupos de visitantes de la RNC (lugareños, turistas nacionales, turistas extranjeros), con el fin de informar la gestión de la experiencia de los visitantes. Se plantearon las siguientes preguntas de investigación:

PI 1: ¿Existen diferencias entre los tres grupos de visitantes en cuanto a las características demográficas o los patrones de visita (en función del sitio de muestreo en el que fueron interceptados)?

PI 2: ¿Cómo experimentan y perciben los sonidos de la RNC los visitantes en general y los tres grupos de visitantes en particular?

Un segundo objetivo fue explorar si los visitantes de la RNC diferencian entre lo que es aceptable, de acuerdo con la misión y objetivos de las APs, y lo que es agradable, de acuerdo con sus preferencias sobre los paisajes sonoros, con el fin de identificar las formas en que los administradores de las APs pueden elaborar programas para desarrollar mejor las estrategias de gestión y de creación de capacidad de gobernanza ciudadana. Se plantearon las siguientes preguntas de investigación:

PI 3: ¿Cómo califican los visitantes en general la aceptabilidad en comparación con la agradabilidad de los sonidos?

PI 4: ¿Existen diferencias en la forma en que los tres grupos de visitantes diferencian los conceptos de aceptabilidad y agradabilidad de los sonidos? 


\section{Evolución del concepto de paisaje sonoro y su investigación}

Para este estudio, los paisajes sonoros representan la consideración holística del ambiente sonoro de un lugar. Incluyen tanto las características físicas del sonido (acústica) como los significados que la gente le asocia. Los paisajes sonoros se han considerado ampliamente desde finales del decenio de 1960 en diversos contextos: la ecología acústica, la ecología del paisaje sonoro, la música y la composición, la calidad del paisaje sonoro, la planificación y el diseño urbanos, la salud y el bienestar y la biología. Desde estos diversos puntos de vista se buscó, de varias maneras, responder a la pregunta, "¿Cuál es la relación entre el hombre y los sonidos de su entorno y qué sucede cuando esos sonidos cambian?" (Schafer, 1977: 3-4). La investigación de Schafer provocó la formación del World Soundscape Project (Orchard et al., 1974; Schafer, 1969; 1974; 1977; Torigoe, 1982; Truax, 1974; 2019), que permitió avanzar en la comprensión de los cambios espacio-temporales del paisaje sonoro en todas las culturas, incluyendo tanto aspectos positivos como negativos de las relaciones humanas con los numerosos entornos sonoros que experimen$\tan$ (Orchard et al., 1974; Torigoe, 1982). El Positive Soundscape Project (Davies et al., 2007; 2009; Davies, 2013), basado en resultados anteriores del World Soundscape Project, puso el foco en la comprensión de las percepciones de los sonidos positivos que deberían preservarse y fomentarse. Ambos proyectos, concentraron la investigación en entornos principalmente urbanos y en sus espacios verdes (Davies et al., 2007).

La investigación del paisaje sonoro en Chile es mucho más reciente. Sommerhoff, Recuero y Suárez (2004) evaluaron la contaminación acústica en la ciudad de Valdivia. Los resultados identificaron que, durante todo el año, en la mayoría de los lugares, el ruido excede la norma diurna, presentando riesgos para la salud de los residentes. El tráfico rodado fue el principal contribuyente al ruido. Posteriormente, Suárez y Barros (2014) elaboraron mapas de ruido de Santiago de Chile, encontrando que el tráfico rodado era, de nuevo, un importante contribuyente a los altos niveles de ruido (> $65 \mathrm{dBA}$ Ld) registrados en el 17,35\% de la superficie modelada dentro de la ciudad. Basándose en proyectos anteriores en Valdivia y Santiago, Suárez y Cárdenas (2015; 2018) desarrollaron mapas sonoros para ambas ciudades, que incluían los mapas de contaminación acústica originales, además de una documentación de los sonidos social y culturalmente relevantes, introduciendo muchos conceptos y variables importantes del paisaje sonoro en documentos diseñados para un público general. Aunque no se ha realizado ningún trabajo previo sobre paisajes sonoros en APs de Chile, Otondo (2018) amplió su trabajo sobre paisajes sonoros en Valdivia, examinando tres humedales urbanos de esta ciudad. Basándose en los comentarios de los visitantes después de escuchar grabaciones del sonido ambiente presentadas en forma de cápsulas, identificó el potencial de los paisajes sonoros para hacer que la gente se implique en la conservación de los humedales. También vio la utilidad de las grabaciones para ayudar a "medir el impacto del ruido antrópico en los hábitats naturales" (Otondo, 2018: 52).

\section{Estudios sobre la percepción de paisajes sonoros en APs naturales}

El interés por el ruido y sus impactos en la biodiversidad y en las experiencias de los visitantes en las APs surgió a fines de la década de 1980 en los Estados Unidos, cuando se aprobó la Ley de Sobrevuelo de Parques Nacionales de 1987 para controlar los impactos del ruido relacionado con las aeronaves (Harbrow et al., 2011). Las investigaciones posteriores sobre el paisaje sonoro han 
ayudado a desarrollar una comprensión de los sonidos y sus impactos en los visitantes y la biodiversidad dentro de una serie de entornos y contextos de APs, aunque hasta la fecha la investigación se ha concentrado en los Estados Unidos, Europa, Australia y Nueva Zelanda (Harbrow et al., 2011). La mayoría de las investigaciones se han referido a los impactos reales y potenciales de los ruidos mecanizados y otros ruidos antrópicos (Harbrow et al., 2011; Rapoza et al., 2015; Weinzimmer et al., 2014), contribuyendo al desarrollo de umbrales, indicadores y normas de calidad (Manning et al., 2006; Marin et al., 2011; Pilcher et al., 2009). Sobre esta base, se ha prestado más atención a la importancia de proteger los paisajes sonoros de los parques naturales. Por ejemplo, el USNPS (Servicio de Parques Nacionales de los Estados Unidos) incluyó la gestión de los paisajes sonoros como parte de su plan general de manejo (USNPS, 2006).

Un número creciente de estudios sobre los paisajes sonoros en APs trata de comprender las percepciones y actitudes de los visitantes. Como resultado, las medidas de aceptabilidad y agradabilidad se han convertido en indicadores comunes de la calidad del sonido percibido (Vittersø et al., 2004; Weinzimmer et al., 2014). Se entiende por aceptabilidad el grado en que un determinado sonido es apropiado en el contexto en el que se percibe. Esta medida ha ayudado a los investigadores y administradores a comprender mejor la forma en que los visitantes entienden los sonidos en el contexto de las APs (Brown et al., 2011; Miller et al., 2018; Taff et al., 2014). La agradabilidad, que expresa el grado en que un sonido es placentero para la persona que lo escucha, también se ha utilizado para medir la calidad del sonido percibido (Axelsson et al., 2010). Por ejemplo, Taff et al. (2014) utilizaron medidas de aceptabilidad para mensurar los efectos de los mensajes educativos relacionados con los ruidos de las aeronaves militares en el Parque Nacional Sequoia. Sobre la base de este trabajo, Miller et al. (2018) destacaron que cada lugar presenta variaciones en cuanto a la cantidad y tipología de sonidos antrópicos, por lo cual, los indicadores deben tener en cuenta su contexto. Identificaron también la necesidad de extender las investigaciones sobre el paisaje sonoro en APs a diferentes culturas, señalando la probabilidad de que surjan diferentes percepciones de los entornos naturales.

Algunos científicos han identificado posibles vínculos entre las investigaciones acústicas que se realizan en entornos urbanos y naturales y las consideraciones psicológicas sobre el sonido y la tranquilidad en los entornos de los parques naturales. Por ejemplo, Mace et al. (2004) conectaron el trabajo de psicología restaurativa de Ulrich et al. (1991), Kaplan (1993) y Kaplan (1995), con la investigación sobre recreación que se estaba llevando a cabo en las APs. Discutieron la importancia de los sonidos naturales en las experiencias de recreación basadas en la naturaleza, y pidieron que la investigación se centrara en la comprensión de los efectos físicos y psicológicos de la exposición al ruido en entornos naturales. Algunos estudios sostienen que la caracterización de los paisajes no puede basarse en descriptores puramente visuales (Watts \& Pheasant, 2015). Tanto los estímulos visuales como auditivos son importantes, y han apoyado la hipótesis de que las evaluaciones realizadas en respuesta a un estímulo unimodal (sólo visual, o sólo sonoro) pueden modificarse en presencia de información bimodal (visual y sonora) (Pheasant et al., 2010). Estos hallazgos también se han extendido al estudio de la experiencia turística, identificando la importancia de una congruencia entre el paisaje sonoro y el visual para proporcionar experiencias más satisfactorias, así como la necesidad de considerar el paisaje sonoro en el diseño y gestión de productos y servicios turísticos (He et al., 2018). Francis et al. (2017) también identificaron la importancia de comprender las percepciones de los visitantes como una potencial herramienta de planificación y gestión, que puede ayudar a superar algunos conflictos 
asociados con el aumento del ruido relacionado con el ser humano y el transporte. Sugirieron que cuando los sonidos naturales predominan en un paisaje sonoro, los beneficios positivos se amplían tanto para los humanos como para los sistemas naturales. Cuando prevalecen los sonidos antrópicos, tanto la biodiversidad como la experiencia de los visitantes se ven perjudicadas. Habida cuenta del rápido aumento de los sonidos antrópicos, incluso en las zonas silvestres, instaron a los investigadores a que estudiaran los efectos de esos paisajes sonoros cambiantes en los sistemas ecológicos y en las personas, con el fin de proteger tanto la biodiversidad como la experiencia de los visitantes.

\section{Material y métodos}

\section{Área de estudio}

La RNC, en la región de Aysén (Chile), se localiza a unos cinco kilómetros de Coyhaique, la capital regional (Figura $\mathrm{N}^{\circ} 1$ ). Abarca 2.643 hectáreas, con áreas de bosque nativo y otras zonas con especies exóticas, plantadas por la necesidad de proteger los suelos que fueron devastados por los incendios acaecidos en la primera mitad del siglo XX (CONAF, 2009). Ofrece una red de senderos de uso público que recorre todos estos entornos, permitiendo visitar varias lagunas, cruzar arroyos y subir a la cima del cerro Cinchao $(1.161 \mathrm{msnm})$, que se alza en un escorial por encima del límite de vegetación. Las actividades más frecuentes son las caminatas del día, el ciclismo y la relajación en las zonas de esparcimiento. Conforme a la legislación chilena, la RNC es una AP de uso múltiple con diversas actividades y objetivos, a veces discordantes. En primer lugar, como Reserva Nacional, debe cumplir ciertos objetivos de conservación de la naturaleza. En segundo lugar, alberga al vivero "Las Lengas", que proporciona árboles para proyectos en toda la región. Tercero, es un espacio importante para el uso público, con activos programas de aprendizaje, ciencia, recreación y turismo. De las 110.537 visitas que se registraron para las APs de la región de Aysén en 2018, 23.404 se realizaron en la RNC, lo cual supone un 21,2\% del total (CONAF, 2018). Finalmente, acoge en su interior desde 2004 al "Programa Manejo Integrado de Plantaciones en la RNC", financiado por el Gobierno Regional de Aysén, que satisface necesidades sociales urgentes en la región. Gracias al manejo de las plantaciones de pino, se proveen productos que ayudan a los sectores más vulnerables de la sociedad. Según datos de 2016, el Programa atendió a más de 118 organizaciones y agrupaciones, con 3.000 familias beneficiadas en la comuna de Coyhaique mediante la provisión de empleos, madera para construir viviendas permanentes y de emergencia y más de $4.600 \mathrm{~m}^{3}$ de leña seca (CONAF, 2017b). Aunque este Programa no está directamente relacionado con el uso público, lo afecta e interactúa con él, ya que una gran parte de sus áreas son visibles, y en algunos puntos transitables, por los visitantes. Así, existen algunos conflictos derivados del desarrollo de las faenas forestales, como el ruido, la presencia de camiones que transportan madera y la visualización de las zonas de volteo de árboles desde los lugares de visita (CONAF, 2017a). 
Figura $\mathrm{N}^{\circ} 1$.

Localización de la RNC y sitios de muestreo

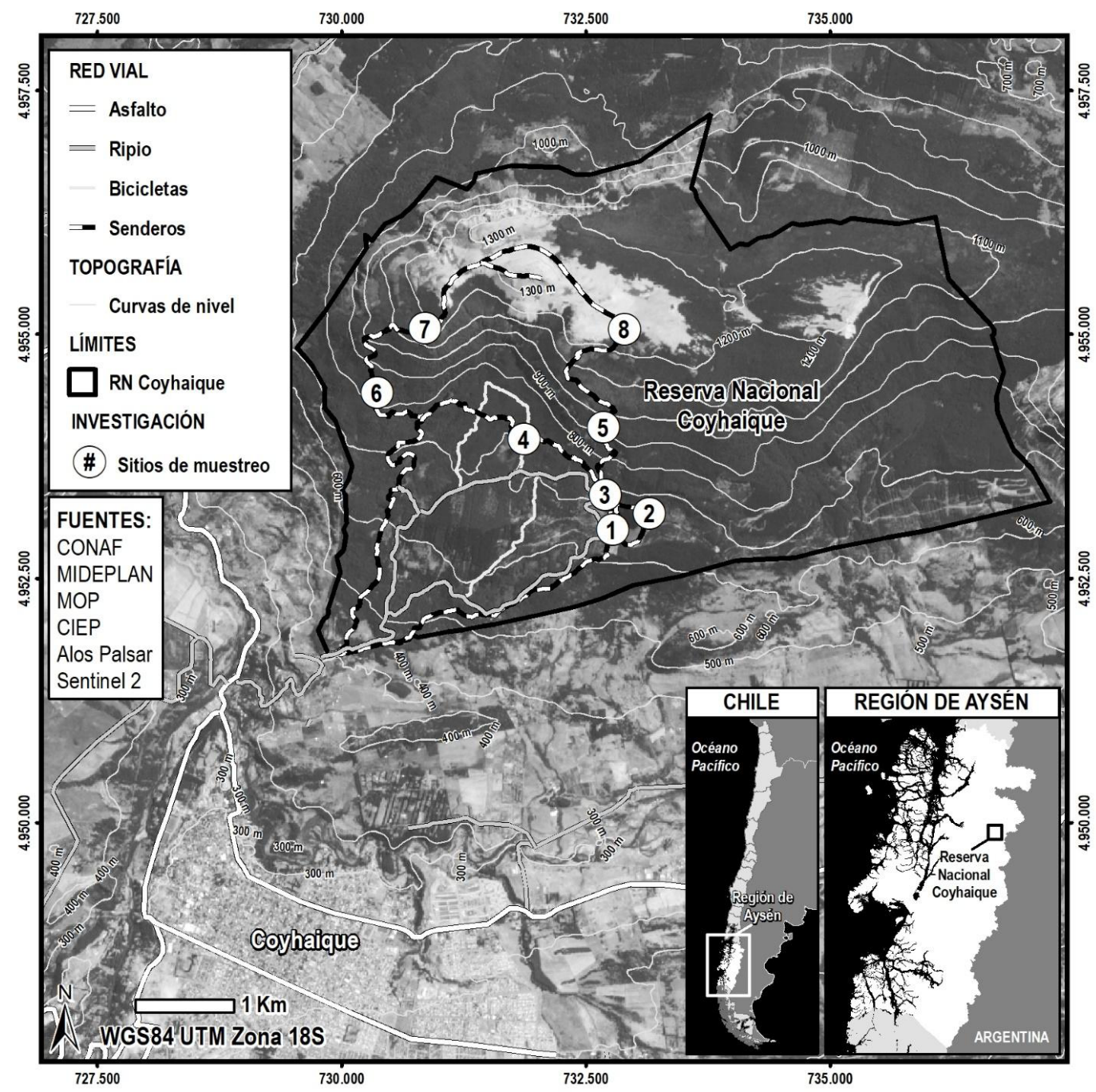

Fuente: Elaboración propia.

\section{Métodos}

Se realizaron encuestas a los visitantes de la RNC en ocho sitios de muestreo repartidos por la red de senderos, que presentan condiciones geográficas y paisajes sonoros diferentes (Figura $\mathrm{N}^{\circ} 1$ ). Los sitios del uno al cuatro se localizan en sectores bajos, cerca de las áreas de manejo de las plantaciones de pino. Soportan un uso público más intenso y tienen un bajo nivel de exigencia física. Los sitios cinco a ocho se encuentran en senderos con una cobertura forestal más natural, pendientes más pronunciadas, mayor demanda física y menos encuentros sociales. Las encuestas, realizadas entre el 14 de enero y el 17 de marzo de 2019, recogieron las impresiones de los visitantes mayores de 18 años que aceptaron los términos del consentimiento informado. Se tomaron datos en uno o dos puntos de muestreo cada día, elegidos mediante un sistema aleatorio, y se 
interceptaron a todas las personas que pasaron por los puntos de muestreo. Para este estudio, se utilizaron tres componentes principales de una encuesta más amplia: datos demográficos de los participantes, un ejercicio de audición y calificaciones sobre la aceptabilidad y agradabilidad de cada sonido percibido. Para el ejercicio de audición, se pidió a los participantes que se sentaran en un lugar cómodo y que se relajaran, concentrándose en la escucha. Los encuestadores cronometraron dos minutos de tiempo, y después pidieron a los participantes que dieran un listado de todos los sonidos que escucharon, los cuales fueron registrados. Después, de acuerdo con el trabajo de monitoreo del paisaje sonoro existente en APs (Miller et al., 2018; Taff et al., 2014), se pidió a los participantes que calificaran cada sonido del listado en cuanto a la aceptabilidad considerando el entorno, y a su agradabilidad, usando escalas de Likert desde -4: muy aceptable a +4: muy inaceptable, y desde -4 : muy agradable $a+4$ : muy desagradable, respectivamente.

\section{Análisis de datos}

La lista de sonidos que los participantes escucharon fue clasificada a través de código abierto. Los investigadores agruparon los sonidos registrados en temas prominentes. Después, trabajaron de manera independiente para reducir la larga lista de temas a un número menor de categorías, y triangularon sus listas individuales para asegurar la confiabilidad interevaluador (Elliott \& Timulak, 2005).

Se completaron pruebas de chi-cuadrado y valores $Z$, con las pruebas $V$ de Cramer para el tamaño del efecto, a fin de identificar diferencias en la prevalencia de los grupos de visitantes interceptados en cada sitio de muestreo. Se utilizaron las medias de las puntuaciones de aceptabilidad y agradabilidad, y los intervalos de confianza del 95\% para representar las evaluaciones de los sonidos para cada grupo de visitantes. Se aplicó la prueba de Wilcoxon para identificar diferencias significativas en las clasificaciones de aceptabilidad y agradabilidad de cada sonido. Se emplearon pruebas de Kruskal-Wallis con las pruebas post-hoc de Kruskal-Nemenyi para identificar diferencias entre la aceptabilidad y la agradabilidad media de los sonidos según el grupo de visitante.

\section{Resultados}

\section{Las características demográficas y las diferencias en los patrones de visita entre los tres grupos de visitantes}

El estudio obtuvo una tasa de respuesta del $81,1 \%$, con 1.108 participantes interceptados y 899 encuestados. En general, la muestra estuvo dominada por turistas nacionales, pero también se obtuvieron representaciones aceptables de lugareños y turistas extranjeros. En cuanto al género, hubo mayor participación de hombres, con la excepción de los turistas nacionales, que tuvieron un porcentaje ligeramente más alto de mujeres. Con respecto a la edad, la mayoría de los participantes (72\%) tenían entre 18 y 35 años. Los turistas extranjeros registraron los mayores porcentajes de personas en los grupos de mayor edad. La mayoría de los participantes realizaron su encuesta en español. Las Figuras $\mathrm{N}^{\circ} 2, \mathrm{~N}^{\circ} 3$, y $\mathrm{N}^{\circ} 4$ contienen las características de la muestra, dividida en los tres grupos de visitantes: lugareños (Coyhaique y Puerto Aysén), turistas nacionales y turistas extranjeros. 
Figura $\mathrm{N}^{\circ} 2$.

Datos demográficos y porcentajes de interceptación por sitio de muestreo - Lugareños

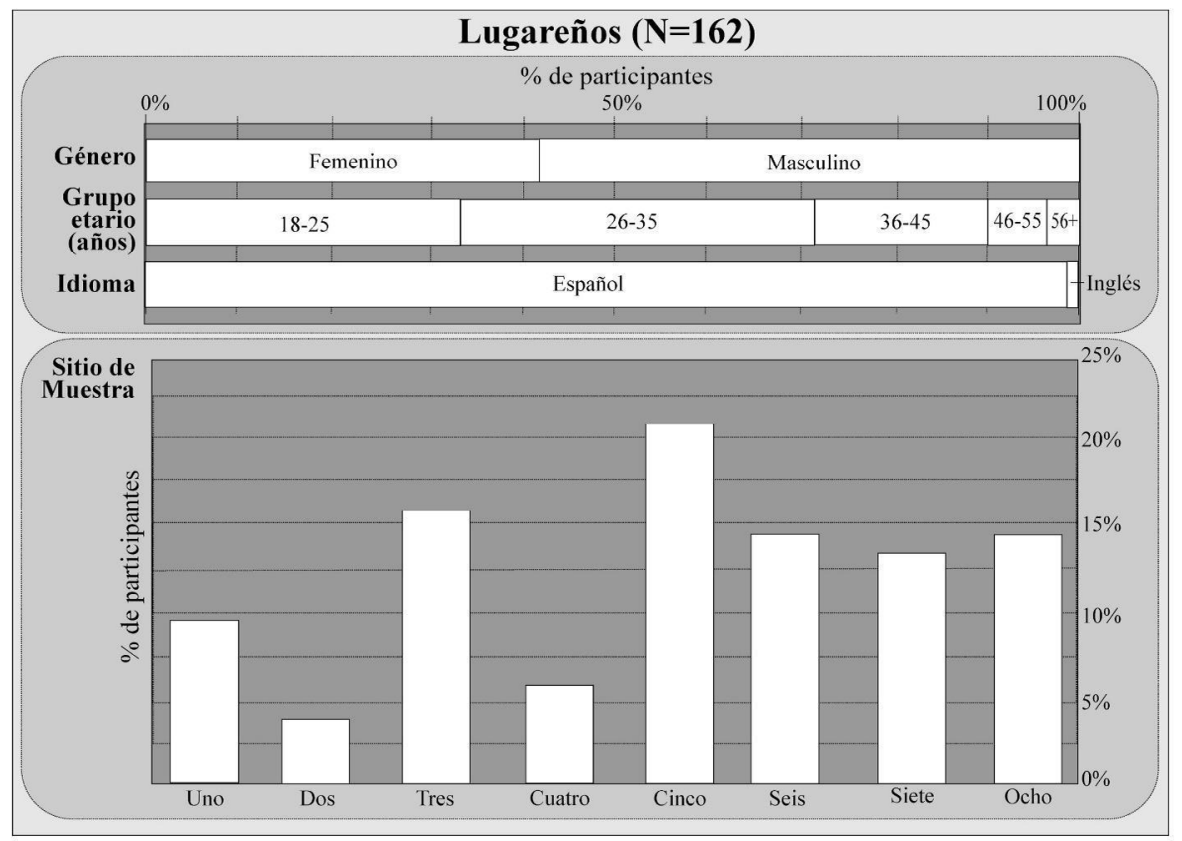

Fuente: Elaboración propia.

Figura $\mathrm{N}^{\circ} 3$.

Datos demográficos y porcentajes de interceptación por sitio de muestreo - Turistas nacionales

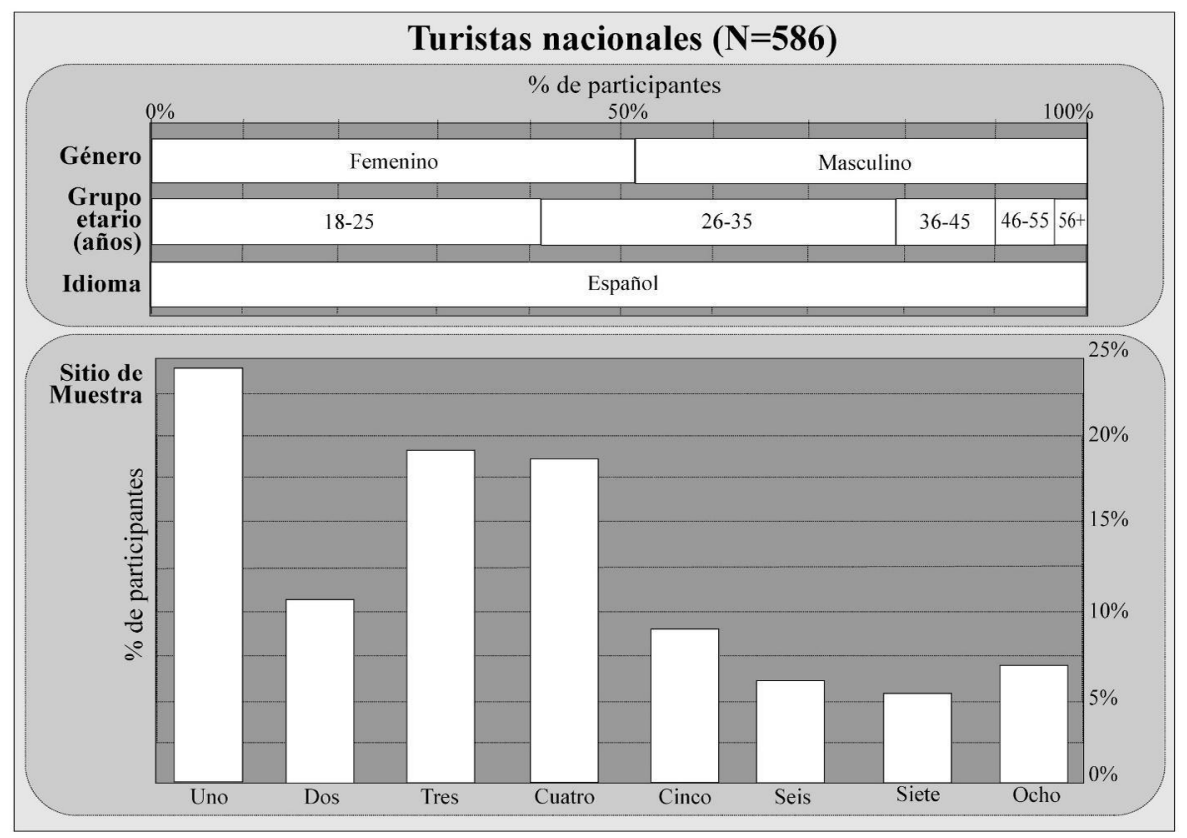

Fuente: Elaboración propia. 
Figura $\mathrm{N}^{\circ} 4$.

Datos demográficos y porcentajes de interceptación por sitio de muestreo - Turistas extranjeros

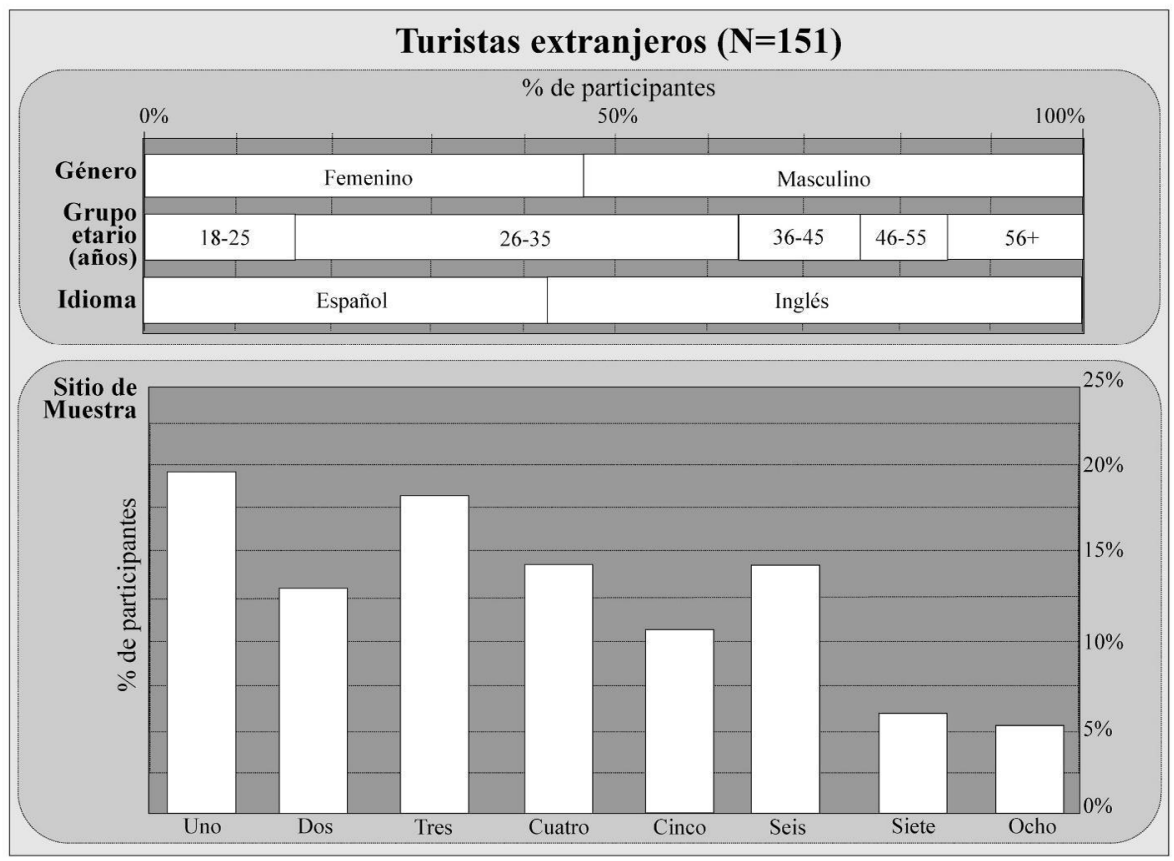

Fuente: Elaboración propia.

No hubo diferencias significativas en la proporción de participantes femeninas y masculinos entre los grupos de visitantes $\left(X^{2}(2)=4,76 ; p=0,09 ; V=0,07\right)$. En cuanto a la edad, los lugareños y los turistas nacionales tendieron a ser más jóvenes en comparación con el grupo de turistas extranjeros. Hubo más participantes lugareños y turistas nacionales que turistas extranjeros en el rango de edad más joven, y más turistas extranjeros que lugareños y turistas nacionales en el rango de edad más avanzada $\left(X^{2}(8)=56,07 ; p=0,00 ; V=0,18\right)$. Los lugareños y turistas nacionales tuvieron significativamente más participantes que realizaron la encuesta en idioma español en comparación con los turistas extranjeros, que albergaron más participantes que hicieron la encuesta en inglés $\left(X^{2}(2)=462,60 ; p=0,00 ; V=0,72\right)$.

Se observaron algunas diferencias significativas en cuanto a los sitios visitados por los grupos de visitantes $\left(X^{2}(14)=91,46 ; p=0,00 ; V=0,23\right)$. Los lugareños fueron interceptados con una frecuencia mayor que los turistas chilenos y extranjeros en los sitios cinco, siete y ocho, que son los de mayor altitud dentro de la RNC. Llegar a ellos implica caminar por un sendero relativamente abrupto, que requiere varias horas para completarlo. Los turistas nacionales y extranjeros frecuentaron más los populares sitios de baja altitud, como los sitios uno y dos, que están cerca de la Laguna Verde, a la que se llega fácilmente en vehículo, o el sitio cuatro, que está en un sendero sin desniveles significativos al que se accede desde la Laguna Verde.

\section{Cómo perciben y experimentan los sonidos los visitantes de la RNC}

La codificación abierta produjo un total de 10 categorías de sonido (Figura №5). Algunos sonidos no pudieron clasificarse debido a la falta de precisión en la descripción, y otros tuvieron una 
escasa representatividad en el conjunto total. Ambos quedaron en la categoría Otros sonidos; algunos ejemplos son: silencio, frío y peces. De las cinco categorías de sonidos naturales, los más frecuentes fueron Viento y Pájaros. Los sonidos antrópicos se percibieron con mucha menos frecuencia y se relacionaron, en gran parte, con Voces humanas, Gente pasando y los sonidos producidos por los participantes, que se clasificaron como Sonidos personales. En proporción a los otros grupos, los turistas extranjeros escucharon menos sonidos naturales y más sonidos antrópicos.

Figura $\mathrm{N}^{\circ} 5$.

Clasificación de los sonidos, descripciones y frecuencias de percepción

\begin{tabular}{|c|c|c|c|c|c|c|c|c|c|}
\hline \multirow[b]{2}{*}{ Categoría } & \multirow{2}{*}{$\begin{array}{l}\text { Descripción de los sonidos } \\
\text { característicos }\end{array}$} & \multicolumn{2}{|c|}{$\begin{array}{l}\text { Lugareños } \\
(\mathbf{N}=162)\end{array}$} & \multicolumn{2}{|c|}{$\begin{array}{c}\text { Turistas } \\
\text { nacionales } \\
(\mathbf{N}=\mathbf{5 8 6})\end{array}$} & \multicolumn{2}{|c|}{$\begin{array}{l}\text { Turistas } \\
\text { extranjeros } \\
(\mathbf{N}=151)\end{array}$} & \multicolumn{2}{|c|}{$\begin{array}{r}\text { Muestra } \\
\text { completa } \\
(\mathrm{N}=899)\end{array}$} \\
\hline & & n & $\%$ & n & $\%$ & n & $\%$ & n & $\%$ \\
\hline Pájaros & $\begin{array}{l}\text { Pájaros en general, sus cantos, aleteos o } \\
\text { especies de pájaros. }\end{array}$ & 118 & $18,4 \%$ & 469 & $19,5 \%$ & 121 & $20,0 \%$ & 708 & $19,3 \%$ \\
\hline Insectos & $\begin{array}{l}\text { Insectos en general, sus zumbidos o } \\
\text { especies de insectos. }\end{array}$ & 52 & $8,1 \%$ & 158 & $6,5 \%$ & 51 & $8,4 \%$ & 261 & $7,1 \%$ \\
\hline Bosque & $\begin{array}{l}\text { Árboles (ramas, crujidos, roturas o } \\
\text { caídas de ramas o frutos, hojas, etc.), } \\
\text { arbustos o pastos. }\end{array}$ & 138 & $21,5 \%$ & 438 & $8,1 \%$ & 76 & $12,6 \%$ & 652 & $17,8 \%$ \\
\hline Viento & $\begin{array}{l}\text { Viento, brisas, aire, ráfagas, etc., } \\
\text { incluyendo interacciones con otros } \\
\text { elementos (viento en ramas, hojas, etc.). }\end{array}$ & 170 & $26,5 \%$ & 645 & $26,7 \%$ & 143 & $23,6 \%$ & 958 & $26,2 \%$ \\
\hline \multirow[t]{2}{*}{ Agua } & $\begin{array}{l}\text { Agua en general, cuerpos (laguna), } \\
\text { corrientes (arroyo, agua corriendo) y } \\
\text { caídas (cascada, lluvia, gotas). }\end{array}$ & 60 & $9,4 \%$ & 253 & $10,5 \%$ & 69 & $11,4 \%$ & 382 & $10,4 \%$ \\
\hline & Subtotal Sonidos Naturales & 538 & $83,9 \%$ & 1.963 & $81,3 \%$ & 460 & $76,0 \%$ & 2.961 & $80,9 \%$ \\
\hline Voces & $\begin{array}{l}\text { Voces y conversaciones, gritos de } \\
\text { personas o niños. }\end{array}$ & 37 & $5,8 \%$ & 157 & $6,5 \%$ & 59 & $9,8 \%$ & 253 & $6,9 \%$ \\
\hline $\begin{array}{l}\text { Gente } \\
\text { pasando }\end{array}$ & $\begin{array}{l}\text { Gente pasando o caminando, pasos, } \\
\text { pisadas. }\end{array}$ & 20 & $3,1 \%$ & 94 & $3,9 \%$ & 25 & $4,1 \%$ & 139 & $3,8 \%$ \\
\hline $\begin{array}{l}\text { Sonidos } \\
\text { personales }\end{array}$ & $\begin{array}{l}\text { Sonidos relacionados con el cuerpo del } \\
\text { encuestado/a (respiración, latidos del } \\
\text { corazón, viento en la cara, en el pelo, en } \\
\text { el oído o en la ropa). }\end{array}$ & 16 & $2,5 \%$ & 43 & $1,8 \%$ & 8 & $1,3 \%$ & 67 & $1,8 \%$ \\
\hline Máquinas & $\begin{array}{l}\text { Sonidos tecnológicos producidos al } \\
\text { interior de la RNC, como vehículos } \\
\text { (autos, camiones, tractores) y sonidos } \\
\text { asociados a trabajos forestales } \\
\text { (motosierras, chipeadoras, etc.). }\end{array}$ & 9 & $1,4 \%$ & 76 & $3,2 \%$ & 17 & $2,8 \%$ & 102 & $2,8 \%$ \\
\hline \multirow[t]{2}{*}{$\begin{array}{l}\text { Aviones, } \\
\text { Ciudad }\end{array}$} & $\begin{array}{l}\text { Sonidos tecnológicos producidos fuera } \\
\text { de la RNC, como motores de aviones, } \\
\text { avionetas, sonidos de la ciudad, sirenas } \\
\text { de bomberos, etc. }\end{array}$ & 9 & $1,4 \%$ & 23 & $1,0 \%$ & 20 & $2,2 \%$ & 52 & $1,4 \%$ \\
\hline & Subtotal Sonidos Antrópicos & 91 & $14,2 \%$ & 393 & $16,3 \%$ & 129 & $21,3 \%$ & 613 & $16,7 \%$ \\
\hline \multirow[t]{2}{*}{$\begin{array}{l}\text { Otros } \\
\text { sonidos }\end{array}$} & $\begin{array}{l}\text { Referencias poco precisas (sonidos no } \\
\text { reconocidos, sonidos de fondo, cielo), } \\
\text { sensaciones (tranquilidad, calma, frío, } \\
\text { etc.), y animales con poca presencia } \\
\text { (sapos, ranas, patos, peces). }\end{array}$ & 12 & $1,9 \%$ & 59 & $2,4 \%$ & 16 & $2,6 \%$ & 87 & $2,4 \%$ \\
\hline & Subtotal Otros Sonidos & 12 & $1,9 \%$ & 59 & $2,4 \%$ & 16 & $2,6 \%$ & 87 & $2,4 \%$ \\
\hline
\end{tabular}

Fuente: Elaboración propia. 


\section{Las percepciones de los participantes sobre la aceptabilidad y agradabilidad de los sonidos de la RNC}

En general, los sonidos naturales se evaluaron de manera más positiva que los antrópicos en cuanto a su aceptabilidad y agradabilidad (Figura $N^{\circ} 6$ ). Los Insectos tuvieron las puntuaciones más bajas de los sonidos naturales, pero mantuvieron cifras positivas. Los Sonidos personales recogieron las puntuaciones más altas dentro de los sonidos antrópicos. Máquinas y Aviones/ Ciudad fueron los únicos sonidos que obtuvieron una evaluación global negativa.

Figura $\mathrm{N}^{\circ} 6$.

Gráfico de líneas de la aceptabilidad y agradabilidad de los sonidos

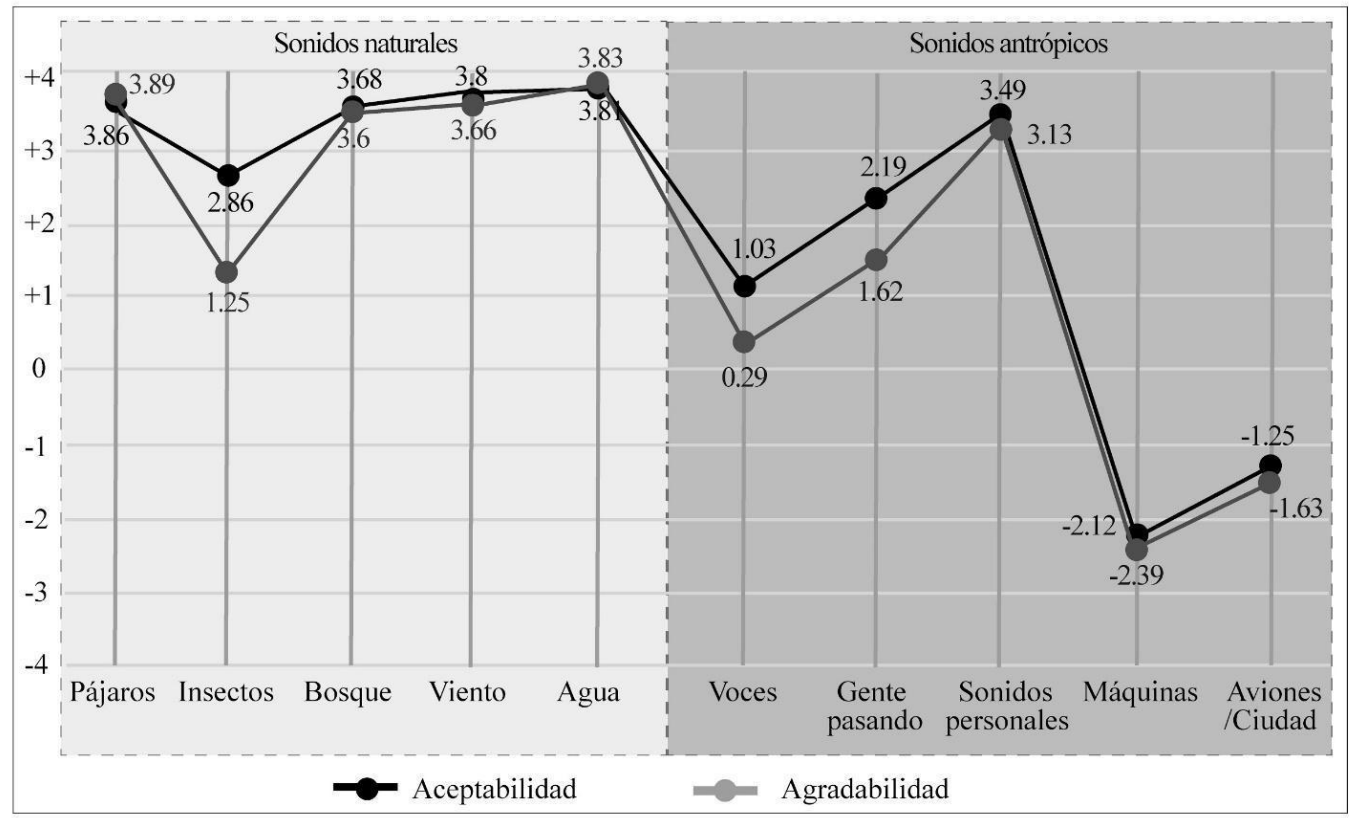

Fuente: Elaboración propia.

La Figura $N^{\circ} 7$ muestra la frecuencia de las percepciones de sonidos de los participantes, junto con su aceptabilidad y agradabilidad. Los sonidos naturales Viento, Pájaros y Bosque fueron los más escuchados, y tuvieron evaluaciones muy positivas tanto de su aceptabilidad como de su agradabilidad. Los Sonidos personales recibieron las puntuaciones más altas de aceptabilidad y agradabilidad de los sonidos antrópicos. Los sonidos naturales tuvieron calificaciones muy similares y consistentes en cuanto a aceptabilidad y agradabilidad, a excepción de Insectos, mientras que los sonidos antrópicos presentaron una mayor variación. 
Figura $\mathrm{N}^{\circ} 7$.

Percepciones de aceptabilidad y agradabilidad de los sonidos de la RNC

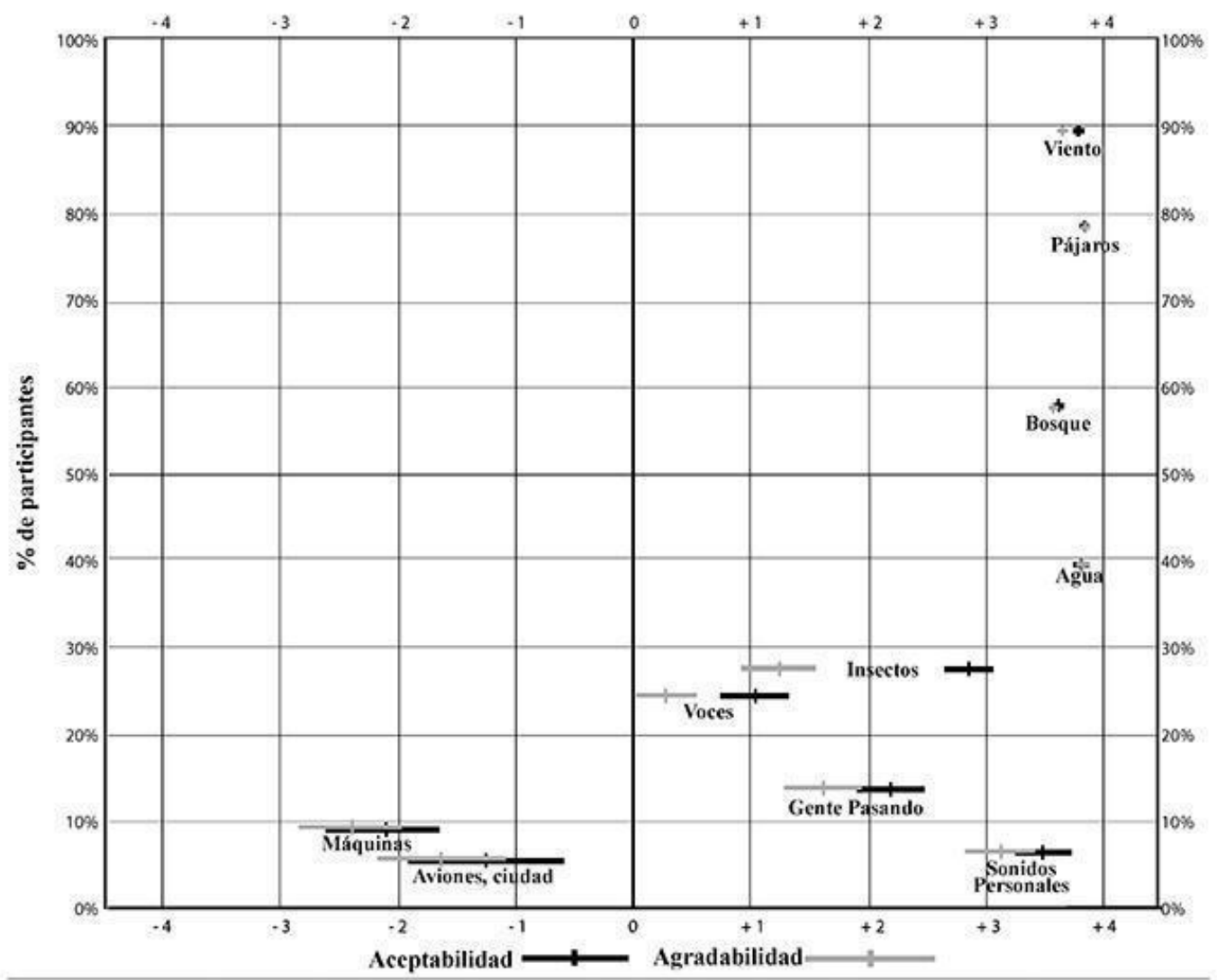

Nota: Las pequeñas lineas verticales indican la media de aceptabilidad y agradabilidad, y las lineas horizontales indican los intervalos de confianza del $95 \%$

Fuente: Elaboración propia.

En general, la prueba de Wilcoxon identificó diferencias significativas en las evaluaciones de aceptabilidad y agradabilidad de los sonidos. En todos los casos en que se produjeron diferencias significativas, la aceptabilidad obtuvo una puntuación más alta que la agradabilidad, específicamente para Insectos $(Z=-9,49 ; p=0,00)$, Bosque $(Z=-2,86 ; p=0,00)$, Viento $(Z=-6,00 ; p=0,00)$, Voces $(Z=-6,00 ; p=0,00)$, Gente pasando $(Z=-4,20 ; p=0,00)$, y Sonidos personales $(Z=-2,73 ; p$ $=0,01)$.

\section{Comparación de cómo los grupos de visitantes diferencian la acepta- bilidad y la agradabilidad de los sonidos}

Las pruebas de Kruskal-Wallis con las pruebas post-hoc de Kruskal-Nemenyi no identificaron ninguna diferencia significativa en las evaluaciones de aceptabilidad, pero sí dos diferencias significativas en las evaluaciones de agradabilidad. Las calificaciones medias de agradabilidad de Bosque fueron más altas para los lugareños que para los turistas nacionales $(H=6,88 ; 2 d f ; p=$ $0,03)$. También, las calificaciones medias de agradabilidad, tanto de los lugareños como de los 
turistas nacionales, fueron más altas que las del grupo de turistas extranjeros para los sonidos del Viento $(H=26,56 ; 2 d f ; p=0,00)$.

La Figura N8 muestra cómo los tres grupos de visitantes diferenciaron la aceptabilidad y la agradabilidad de cada sonido. Para los Insectos, no hubo superposición de los intervalos de confianza del $95 \%$ en ninguno de los tres grupos. Lo mismo pasa con el Viento, pero esta vez sólo para los turistas nacionales y extranjeros. En el caso de Gente pasando, aunque hay superposiciones, se observa una marcada diferencia en las clasificaciones de aceptabilidad y agradabilidad para los tres grupos de visitantes.

Figura $\mathrm{N}^{\circ} 8$.

Percepciones de aceptabilidad y agradabilidad de los sonidos para los tres grupos de visitantes

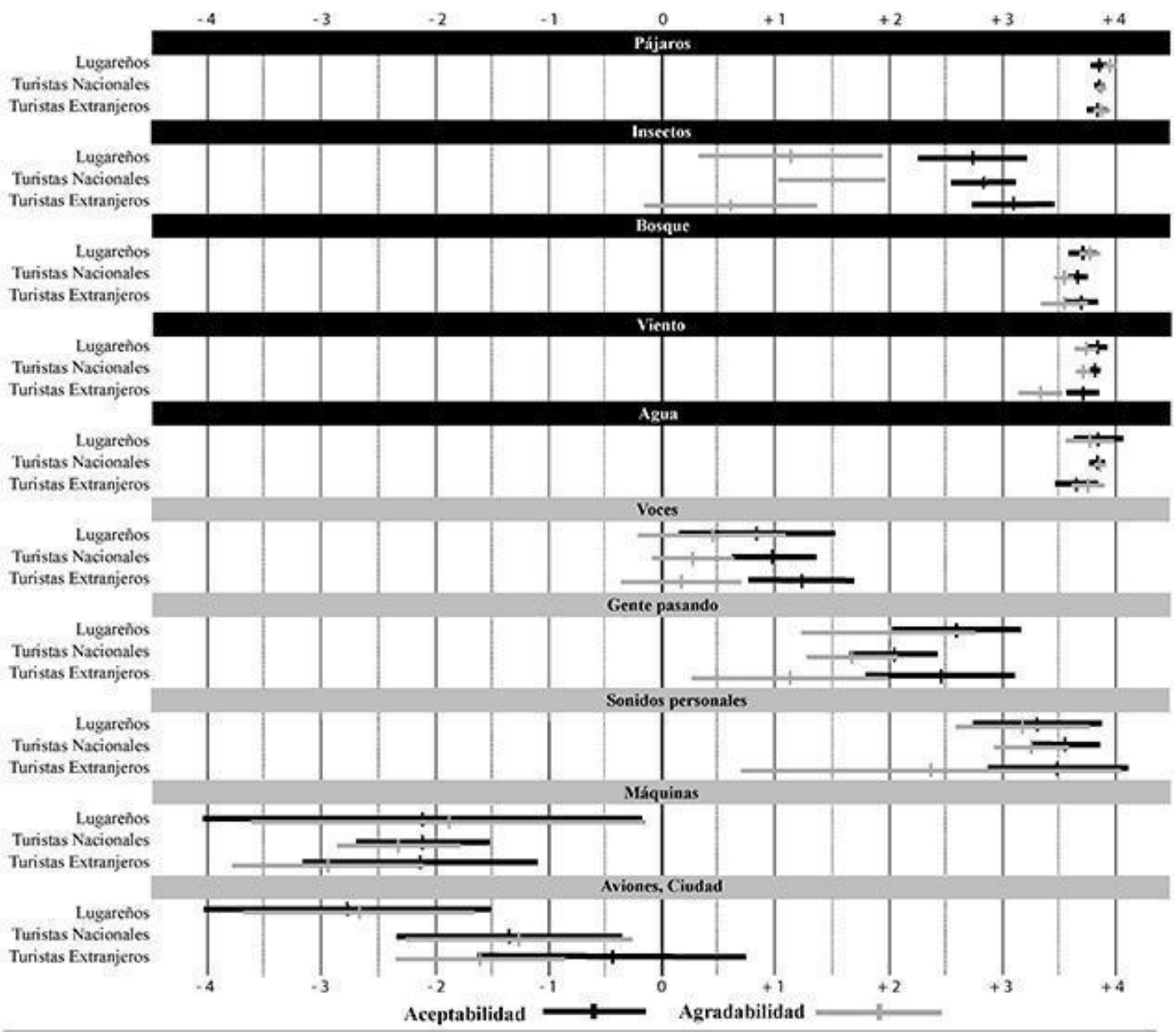

Nota: Las pequeñas lineas verticales indican la media de aceptabilidad y agradabilidad, $y$ las lineas horizontales indican los intervalos de confianza del $95 \%$

Fuente: Elaboración propia. 


\section{Discusión}

Al parecer, los participantes del estudio disfrutaron mucho de la actividad de audición consciente de los sonidos dentro del AP. Muchos agradecieron la petición de sentarse y escuchar, y mencionaron que en el futuro pondrán más atención a los sonidos como resultado de la actividad.

Las categorías Viento, Pájaros, Bosque y Agua se encuentran entre los sonidos más escuchados, y sus calificaciones superiores a 3,5 en una escala de -4 a +4 , demuestra que los visitantes de la RNC disfrutan de los paisajes sonoros naturales. Las percepciones sobre la aceptabilidad y la agradabilidad son muy similares en las categorías Pájaros, Bosque y Agua, reflejado en la corta longitud de las líneas que representan los intervalos de confianza del 95\%. Tal y como apuntan algunos autores, comprender estas percepciones es una potencial herramienta para la planificación y gestión (Francis et al., 2018; He et al., 2018). Estas categorías de sonidos son buenos referentes para fijar los objetivos de conservación del Plan de Manejo de la RNC; además, los resultados sirven como una validación (1) de la comprensión de los visitantes de la idoneidad de estos aspectos naturales dentro de la RNC, (2) de que disfrutan escuchando sus sonidos asociados, y (3) de que los actuales senderos y áreas de visita ofrecen amplias posibilidades para escuchar estos sonidos. Las percepciones sobre el Viento, que fue escuchado por el $89 \%$ de los participantes, demuestran la importancia de incluir tanto la aceptabilidad como la agradabilidad dentro de la encuesta. Aunque los participantes califican tanto la aceptabilidad como la agradabilidad de este sonido con puntuaciones medias superiores a 3 , las diferencias en estas calificaciones indican un mayor espectro de percepciones y una clara diferenciación conceptual. Los participantes distinguen claramente estos dos conceptos, evaluando el Viento como menos agradable que aceptable, sin superposición de medias o intervalos de confianza. Acá aparece un ejemplo de la necesidad de contextualizar el lugar a la hora de establecer indicadores para el monitoreo (Miller et al., 2018). Desde el punto de vista de la gestión, el viento es uno de los aspectos que definen el clima de la Patagonia y un elemento fundamental en sus ecosistemas. Por tanto, no es extraño que sea la categoría más escuchada, dada su intensidad y la exposición que se siente en muchos lugares dentro de la RNC. Las altas puntuaciones de aceptabilidad de esta categoría son otra validación de la comprensión general por parte de los visitantes de lo que cabe esperar en el entorno de la RNC. Las percepciones de aceptabilidad y agradabilidad también están menos alineadas en Insectos y en todos los sonidos antrópicos, especialmente en Voces, que no muestran superposición en las medias o en los intervalos de confianza, así como en las categorías de sonidos tecnológicos, Máquinas y Aviones/Ciudad, en los que los intervalos de confianza se expanden mucho respecto de sus valores medios.

Curiosamente, la agradabilidad de los Insectos, de los cuales casi la mitad aluden a aquellos que muerden y pican, se califica positivamente $(1,25$ en la escala de -4 a +4$)$. No obstante, la evaluación general de su aceptabilidad es más alta (media $=2,86$ ). De hecho, no hay superposición entre ellas, y se ve una notable brecha entre los intervalos de confianza. Estudios anteriores realizados en Estados Unidos, incluido el de Miller et al. (2018), obtuvieron resultados diferentes, con calificaciones de agradabilidad negativas. Cabría esperar calificaciones de agradabilidad igualmente bajas en la RNC, ya que las mordeduras y picaduras de los insectos traen molestias, pero no es así. Las evaluaciones de los participantes sugieren un aprecio por los sonidos de los Insectos, independientemente de su especie. De todos modos, su clara diferenciación entre 
aceptabilidad y agradabilidad respalda un reconocimiento a la vez que un desagrado hacia estos sonidos, a pesar de que son una parte natural del ecosistema. En Miller et al. (2018), los sonidos de los insectos fueron escuchados por la mayoría de los participantes, mientras que menos del $30 \%$ de los encuestados en la RNC los oyeron. Amerita entonces investigar con mayor profundidad cómo la prevalencia de los insectos puede afectar a las percepciones de los visitantes, y en qué medida la agradabilidad de sus sonidos varía en las distintas culturas y regiones.

Cualitativamente, se observaron diferencias entre los lugareños, los turistas nacionales y los turistas extranjeros con respecto a las frecuencias con las que experimentaron los sonidos en la RNC. Por ejemplo, los lugareños percibieron los sonidos del Bosque proporcionalmente con mayor frecuencia que los turistas nacionales y extranjeros. Estos sonidos representaron el 21,53\% de los estímulos escuchados por los lugareños, el $18,14 \%$ de los escuchados por los turistas nacionales y sólo el $12,56 \%$ en el caso de los turistas extranjeros. Los resultados de la prueba de Kruskal-Wallis demuestran que los lugareños encuentran los sonidos del Bosque más agradables que los turistas nacionales, lo que sugiere que los lugareños no sólo perciben estos sonidos más a menudo, también que los disfrutan más. Tal vez los lugareños ocupen el conocimiento local para buscar sus estímulos ambientales preferidos durante sus visitas a la RNC (por ejemplo, los entornos forestales), lo cual les permite cumplir mejor sus expectativas. Los resultados de la categoría Voces apoyan aún más esta teoría. Los turistas extranjeros tienden a percibir Voces más frecuentemente que los lugareños. Estos sonidos representan uno de cada 10 estímulos escuchados por los turistas extranjeros y uno de cada 17 escuchados por los lugareños. Los intervalos de confianza del 95\% para la agradabilidad de las Voces se extendieron a los valores de calificación negativa para los tres grupos de visitantes. Esto indica que los tres grupos preferirían experiencias auditivas con menos sonidos de voz humana. Sin embargo, los lugareños, que informaron oír Voces con menos frecuencia, tienden a frecuentar lugares más naturales y con menos encuentros sociales, en comparación con ambos grupos de turistas, que frecuentan sitios de uso intensivo, más asequibles y con menos cobertura forestal.

Además de las similitudes y diferencias examinadas para la muestra global, un análisis más profundo identifica diferencias entre los tres grupos de visitantes. Si bien todos diferenciaron entre la aceptabilidad y la agradabilidad de los sonidos de los Insectos, los turistas nacionales, y especialmente los extranjeros, tienden a diferenciar estos dos conceptos de manera más acentuada que los lugareños. Por ejemplo, los turistas extranjeros califican la aceptabilidad de Voces más de un punto por encima respecto de su agradabilidad, sin que se superpongan los intervalos de confianza. Los turistas nacionales también diferencian claramente los conceptos, con muy poca superposición $(0,03)$ en los intervalos de confianza. Las evaluaciones de aceptabilidad y agradabilidad de Voces se superponen mucho más y son similares para los lugareños. Quizás los turistas extranjeros y nacionales dan calificaciones más altas de la aceptabilidad de las Voces que los lugareños porque su presencia en la RNC fue menor que lo que típicamente experimentan en su entorno de origen, o en APs de otras regiones del mundo. Sin embargo, los turistas extranjeros y nacionales califican las Voces como menos agradables que los lugareños. Tal vez esto se relaciona con la mayor presencia de personas en los sitios más asequibles, donde estuvieron expuestos a un mayor volumen de las Voces. Alternativamente, esto apoya las indicaciones previas sobre las diferencias culturales/regionales acerca de las expectativas sobre los entornos y los comportamientos sociales apropiados en un AP (Miller et al., 2018), observando a 
los lugareños, que se decantaron por áreas naturales y con menos encuentros sociales. Un patrón similar, pero menos marcado, surge de la forma en que los tres grupos califican la aceptabilidad y la agradabilidad de los sonidos de la Gente pasando. En este caso, los turistas extranjeros diferencian más la aceptabilidad de la agradabilidad que los lugareños, aunque sus calificaciones medias de aceptabilidad son similares (2,48 y 2,6, respectivamente). Por parte de los turistas extranjeros, hay poca superposición en el intervalo de confianza del $95 \%$ entre la aceptabilidad y la agradabilidad mientras que las calificaciones de los lugareños se superponen mucho más. Las puntuaciones medias de agradabilidad de los turistas extranjeros fueron notablemente más bajas que las de los lugareños (1,12 y 2, respectivamente). Estos resultados sugieren que, si bien los lugareños pueden preferir zonas con menos voces y más sonidos naturales, siguen apreciando los encuentros sociales en la RNC. Es posible que los residentes de las cercanas ciudades de Coyhaique y Puerto Aysén disfruten compartiendo su escapada con su comunidad y con visitantes de otras partes de Chile y de otros países; pero prefieren encuentros sociales más discretos, ya que se circunscriben a los senderos.

Todavía no se conoce a cabalidad el impacto de los paisajes sonoros en la regulación de los procesos ecológicos y en la experiencia humana, pero los antecedentes científicos apuntan a que ejercen un rol más importante de lo que se habría podido imaginar hace tan solo diez años (Francis et al., 2017). El presente artículo aboga justamente por incorporar el estudio de los paisajes sonoros a las prácticas habituales de gestión del uso público en APs, apuntando hacia una comprensión más amplia de la experiencia del visitante y a las repercusiones que esto debería tener en la toma de decisiones (Francis et al., 2017; He et al. 2018; Hall et al., 2010; Hvenegaard, 2017). La tendencia hacia enfoques más holísticos en la gobernanza involucrará a un segmento más amplio de ciudadanos y visitantes (Ladrón de Guevara, 2014; Petit et al., 2018; Subsecretaría de Turismo, 2017) y la complejidad de las relaciones ser humano-medio ambiente requiere la consideración de múltiples elementos para su estudio. El conocimiento de la percepción de los paisajes sonoros por parte de todos los actores involucrados en el devenir de las APs: la CONAF (Corporación Nacional Forestal) como administradores y otros servicios públicos, consejos consultivos, mesas científicas, concesionarios, visitantes, etc., y su pertinente aplicación, puede representar una valiosa herramienta para la gestión y la gobernanza, informando el establecimiento de objetivos que afecten tanto a la protección y conservación de la naturaleza como a la provisión de experiencias de calidad. En este escenario, se hace más relevante el rol de las mesas científicas en la asesoría, organización y planificación de investigaciones y programas educativos al respecto, y en el establecimiento de estándares coherentes con la categoría del AP (Parque, Reserva, Monumento Natural), ajustados según el contexto específico del lugar. De igual modo, los concesionarios y operadores turísticos, además de poder ofrecer mejores servicios y productos gracias al buen manejo de los sonidos, podrían ampliar su compromiso realizando tareas de monitoreo, actividad que también es extensible a prácticas laborales para alumnos universitarios, lo cual incentivaría o reforzaría los acuerdos de colaboración entre CONAF y Centros Educacionales y de Investigación. Esto son sólo algunos ejemplos de cómo el estudio de las percepciones del paisaje sonoro puede involucrar a diferentes segmentos de la ciudadanía y facilitar acciones de gobernanza y gestión, que podrían ampliarse conforme se vaya consolidando esta práctica. 


\section{Conclusión}

Los resultados de esta investigación sustentan la importancia del estudio de las experiencias de los visitantes con el paisaje sonoro como un elemento importante en la gestión de las APs, que merece una mayor consideración y aplicación en Chile.

En los próximos años, se espera que en Chile se produzcan importantes cambios a corto y largo plazo relacionados con el aumento de la participación y la gobernanza ciudadana (Maldonado et al., 2019). Considerando lo que representan las APs para las regiones de Aysén y Magallanes de Chile, debe considerarse prioritario preparar a sus habitantes para contribuir significativamente a su gobernanza y a la gestión de experiencias de calidad. Teniendo en cuenta que la gobernanza implica, entre otras cosas, definir cuáles son los objetivos, qué hacer para alcanzarlos y con qué medios (Borrini-Feyerabend \& Hill, 2015), una mejor comprensión de los paisajes sonoros y de las formas en que se perciben puede ser de gran ayuda.

Aunque se requiere investigación adicional, este artículo destaca la importancia de un desarrollo continuo de las experiencias, en este caso, informada a través de estudios sobre cómo los distintos grupos de visitantes perciben e interpretan los estímulos sonoros. Programas educativos sobre esta temática dentro de la RNC podrían aumentar la consistencia entre la aceptabilidad y la agradabilidad de los sonidos naturales con peor calificación, como viento e insectos, y mejorar la aceptabilidad de los sonidos antrópicos que son inherentes a los usos de la RNC, como las máquinas para el manejo forestal.

En otras partes del mundo las APs han aplicado programas educativos para que la población local desarrolle habilidades como naturalistas e intérpretes (Nordic Council of Ministers, 2019). El alto interés de los lugareños en los paisajes sonoros de la RNC y en compartirla con otros visitantes, hace pensar que hay una buena oportunidad para programas similares en Chile. Estos programas no sólo podrían ayudar a mejorar las experiencias, también podrían instruir a los ciudadanos para evolucionar y apoyar más activamente los objetivos de manejo de las APs, así como las iniciativas que abogan por una mayor equidad y calidad de vida.

Dado que la RNC es un AP con múltiples usos, es preciso que los residentes locales desarrollen una comprensión holística de este espacio y de los servicios ecosistémicos y sociales que proporciona. El estudio continuado de las percepciones sobre los paisajes sonoros suministrará nuevas herramientas a los administradores y tomadores de decisiones que pueden contribuir a ello, e informar la educación y el diálogo con los actores clave, con objeto de ampliar las posibilidades de una gobernanza ciudadana eficaz y la gestión y monitoreo de sus recursos.

Agradecimientos: Se agradece la contribución de María José Oyarzo, Javier Poblete, Paola Torres y José Cuevas como parte del equipo en terreno. 


\section{Referencias}

AXELSSON, O., NILSSON, M. \& BERGLUND, B. A principal components model of soundscape perception. Journal of the Acoustical Society of America, 2010, no. August, p. 555-560. https://doi. org/10.1007/978-1-4419-0561-1_48

BORRINI-FEYERABEND, G. \& HILL, R. Governance for the conservation of nature. En: WORBOYS, G. L.; LOCKWOOD, M.; KOTHARI, A.; FEARY, S. \& PULSFORD, I. (eds.) Protected Area Governance and Management. Canberra; ANU Press, 2015, p. 169-206.

BROWN, A.L., KANG, J. \& GJESTLAND, T. Towards standardization in soundscape preference assessment. Applied Acoustics, 2011, Vol. 72, Nº6, p. 387-392. DOI 10.1016/j.apacoust.2011.01.001.

CORPORACIÓN NACIONAL FORESTAL (CONAF). Plan de Manejo Reserva Nacional Coyhaique. Documento de Trabajo N525. Coyhaique, 2009.

CORPORACIÓN NACIONAL FORESTAL (CONAF). Plan de uso público de la Reserva Nacional Coyhaique. PTDASPE - Región de Aysén. Coyhaique, 2017a.

CORPORACIÓN NACIONAL FORESTAL (CONAF). Programa Manejo de Plantaciones: 13 años de aporte laboral, social y ambiental, 2017b. (Consulta: 31/01/2020). http://www.conaf.cl/programa-manejo-de-plantaciones-13-anos-de-aporte-laboral-social-y-ambiental/.

CORPORACIÓN NACIONAL FORESTAL (CONAF). Estadística Visitantes Unidades SNASPE para el año 2018. Gerencia de Áreas Protegidas - Sección de Control de Gestión y Presupuesto. Santiago de Chile, 2018. Disponible en: http://www.conaf.cl/wp-content/files_mf/1561061927EstadisticaTot_año_2018.pdf.

DAVIES, W.J., ADAMS, M.D., BRUCE, N.S., CAIN, R., CARLYLE, A., CUSACK, P., HUME, K.I., JENNINGS, P.A. \& PLACK, C.J. The positive soundscape project. 19th Inrernational Congress On Acoustics [en línea], 2007. Disponible en: http://usir.salford.ac.uk/2460/.

DAVIES, W.J., ADAMS, M.D., BRUCE, N., MARSELLE, M., CAIN, R., JENNINGS, P., POXON, J., CARLYLE, A., CUSACK, P., HALL, D.A., IRWIN, A., HUME, K.I. \& PLACK, C.J. The positive soundscape project: a synthesis of results from many disciplines. Internoise 2009: Innovations in practical noise control. Ottawa, CA, 2009. Disponible en: http://usir.salford.ac.uk/2106/.

DAVIES, W.J. Special issue: Applied soundscapes. Applied Acoustics, 2013, Vol. 74, №2, p. 223. http://dx.doi.org/10.1016/j.apacoust.2012.07.004.

ELLIOTT, R. \& TIMULAK, L. Descriptive and interpretive approaches to qualitative research. En: J. MILES \& P. GILBERT (eds.) A handbook of research methods for clinical and health psychology. Oxford; Oxford University Press, 2005, p. 147-159. 
FARINA, A. Soundscape ecology: Principles, patterns, methods and applications. Berlín: Springer Netherlands, 2014.

FEDREHEIM, G.E. \& BLANCO, E. Co-management of protected areas to alleviate conservation conflicts: Experiences in Norway. International Journal of the Commons, 2017, Vol. 11, N², p. 754-773. https://doi.org/10.18352/ijc.749

FRANCIS, C.D., NEWMAN, P., TAFF, B.D., WHITE, C., MONZ, C.A., LEVENHAGEN, M., PETRELLI, A.R., ABBOTT, L.C., NEWTON, J., BURSON, S., COOPER, C.B., FRISTRUP, K.M., MCCLURE, C.J.W., MENNITT, D., GIAMELLARO, M. \& BARBER, J.R. Acoustic environments matter: Synergistic benefits to humans and ecological communities. Journal of Environmental Management [en línea], 2017, Vol. 203, p. 245-254. https://doi.org/10.1016/j.jenvman.2017.07.041.

HALL, T.E., SEEKAMP, E. \& COLE, D. Do recreation motivations and wilderness involvement relate to support for wilderness management? A segmentation analysis. Leisure Sciences, 2010, Vol. 32, №2, p. 109-124. https://doi.org/10.1080/01490400903547096.

HAMILTON, L. \& JEPSON, P. Conflict in Crocker: Applying ethical analysis to constructive dialogue in a co-managed protected area in Sabah (Malaysia). Environmental Conservation, 2017, Vol. 44, №2, p. 166-173. https://doi.org/10.1017/S0376892916000345.

HARBROW, M.A., CESSFORD, G.R. \& KAZMIEROW, B.J. The impact of noise on recreationists and wildlife in New Zealand's natural areas: A literature review. Wellington, 2011.

HE, M., LI, JINGWEN, LI, JUN \& CHEN, H. A comparative study on the effect of soundscape and landscape on tourism experience. International Journal of Tourism Research, 2019, p. 1-12. https:// doi.org/10.1002/jtr.2237.

HILLIER, J. Politics of The Ring: Limits to Public Participation in Engineering Practice. International Journal of Urban and Regional Research, 2018, Vol. 42, N², p. 334-356. https://doi.org/10.1111/14682427.12523.

HVENEGAARD, G.T. Visitors' perceived impacts of interpretation on knowledge, attitudes, and behavioral intentions at Miquelon Lake Provincial Park, Alberta, Canada. Tourism and Hospitality Research, 2017, Vol. 17, №1, p. 79-90. https://doi.org/10.1177/1467358416634157.

KAPLAN, R. The role of nature in the context of the workplace. Landscape and Urban Planning, 1993, Vol. 26, No1-4, p. 193-201. https://doi.org/10.1016/0169-2046(93)90016-7.

KAPLAN, S. The restorative benefits of nature: Toward an integrative framework. Journal of Environmental Psychology, 1995, Vol. 15, p. 169-182.

LADRÓN DE GUEVARA, J. Proposal of a financial strategy for the Protected Areas National System - Chile: Executive Summary. Santiago de Chile, 2014. 
MACE, B.L., BELL, P.A. \& LOOMIS, R.J. Visibility and natural quiet in national parks and wilderness areas: Psychological considerations. Environment and Behavior, 2004, Vol. 36, N¹, p. 5-31. https:// doi.org/10.1177/0013916503254747.

MALDONADO, L., CASTILLO, J.C., ITURRA, J., ATRIA, J. \& MENESES, F. La demanda por igualdad y los caminos que cuentan con amplio respaldo ciudadano. CIPER Chile, 2019, p. 1-14.

MANNING, R., VALLIERE, W., HALLO, J., NEWMAN, P., PILCHER, E., SAVIDGE, M. \& DUGAN, D. From landscapes to soundscapes: Understanding and managing natural quiet in the national parks. En: R. BURNS y K. ROBINSON (eds.), Proceedings of the 2006 Northeastern Recreation Research Symposium. Bolton Landing; New York: U.S. Forest Service, Northern Research Station, 2006, p. 601-606.

MARIN, L.D., NEWMAN, P., MANNING, R., VASKE, J.J. \& STACK, D. Motivation and acceptability norms of human-caused sound in Muir Woods National Monument. Leisure Sciences, 2011, Vol. 33 , N², p. 147-161. https://doi.org/10.1080/01490400.2011.550224.

MEES, H., CRABBÉ, A. \& DRIESSEN, P.P.J. Conditions for citizen co-production in a resilient, efficient and legitimate flood risk governance arrangement. A tentative framework. Journal of Environmental Policy and Planning, 2017, Vol. 19, Nº6, p. 827-842. https://doi.org/10.1080/152390 8X.2017.1299623.

MILLER, N. Understanding Soundscapes. Buildings, 2013, Vol. 3, №4, p. 728-738. https://10.3390/ buildings 3040728 .

MILLER, Z.D., TAFF, B.D. \& NEWMAN, P. Visitor Experiences of Wilderness Soundscapes in Denali National Park and Preserve. International Journal of Wilderness, 2018, Vol. 24, N², p. 32-43.

MINISTERIO DEL MEDIO AMBIENTE. Las Áreas Protegidas de Chile: Antecedentes, institucionalidad, estadísticas y desafíos. División de Recursos Naturales Renovables y Biodiversidad. Santiago de Chile, 2011.

NORDIC COUNCIL OF MINISTERS. Visitor Management in Nordic National Parks. Copenhagen: Nordic Council of Ministers, 2019.

ORCHARD, I., TRUAX, B. \& BROOMFIELD, H. Commentary: Aural history and the World Soundscape Project. Sound Heritage, 1974, Vol. 3, N4, p. 4-9.

OTONDO, F. Listening To Wetland Soundscapes. Leonardo Music Journal, 2018, Vol. 28, p. 50-52.

PETIT, I.J., CAMPOY, A.N., HEVIA, M.J., GAYMER, C.F. \& SQUEO, F.A. Protected areas in Chile: Are we managing them? Revista Chilena de Historia Natural, 2018, Vol. 91, N¹, p. 1-8. https://doi. org/10.1186/s40693-018-0071-z. 
PHEASANT, R.J., FISHER, M.N, WATTS, G.R. WHITAKER, D.J., HOROSHENKOV, K.V. The importance of auditory-visual interaction in the construction of 'tranquil space'. Journal of Environmental Psychology. 2010, Vol 30, p. 501-509. https://doi.org10.1016/j.jenvp.2010.03.006

PIETILÄ, M. Do Visitor Experiences Differ Across Recreation Settings? Using Geographical Information Systems to Study the Setting-Experience Relationship. Visitor Studies, 2017, Vol. 20, №2, p. 187-201. https://doi.org/10.1080/10645578.2017.1404350.

PILCHER, E.J., NEWMAN, P. \& MANNING, R.E. Understanding and Managing Experiential Aspects of Soundscapes at Muir Woods National Monument. Environmental Management, 2009, Vol. 43, p. 425-435. https://doi.org/10.1007/s00267-008-9224-1.

RAPOZA, A., SUDDERTH, E. \& LEWIS, K. The relationship between aircraft noise exposure and dayuse visitor survey responses in backcountry areas of national parks. The Journal of the Acoustical Society of America, 2015, Vol. 138, N4, p. 2090-2105. https://doi.org/10.1121/1.4929934.

SANDSTRÖM, A., CRONA, B. \& BODIN, Ö. Legitimacy in co-management: The impact of preexisting structures, social networks and governance strategies. Environmental Policy and Governance, 2014, Vol. 24, N¹, p. 60-76. https://doi.org/10.1002/eet.1633.

SCHAFER, R.M. The new soundscape: A handbook for the modern music teacher. Ontario, CA: BMI Canada Limited, 1969.

SCHAFER, M. Listening. Sound Heritage, 1974, vol. 3, no. 4, p. 10-17.

SCHAFER, R.M. The soundscape: our sonic environment and the tuning of the world. Rochester, Vt.: Destiny Books, 1977.

SOLIKU, O. \& SCHRAML, U. Making sense of protected area conflicts and management approaches: A review of causes, contexts and conflict management strategies. Biological Conservation, 2018, Vol. 222, p. 136-145. https://doi.org/10.1016/j.biocon.2018.04.011.

SOMMERHOFF, J., RECUERO, M. \& SUÁREZ, E. Community noise survey of the city of Valdivia, Chile. Applied Acoustics, 2004, Vol. 65, N7, p. 643-656. https://doi.org/10.1016/j.apacoust.2004.01.003.

SUÁREZ, E. \& BARROS, J.L. Traffic noise mapping of the city of Santiago de Chile. Science of the Total Environment, 2014, Vol. 466-467, p. 539-546. https://doi.org/10.1016/j.scitotenv.2013.07.013.

SUÁREZ S., E. \& CÁRDENAS M., J. Mapa Sonoro de Valdivia. Valdivia. Chile: Maval Ltda., 2015.

SUÁREZ S., E. \& CÁRDENAS M., J. Mapa sonoro de la zona centro del Gran Santiago. Valdivia, Chile: América Ltda., 2018.

SUBSECRETARÍA DE TURISMO. Turismo Sustentable en Áreas Protegidas del Estado: Una apuesta de presente y futuro. Santiago de Chile, 2017. Disponible en: http://www.subturismo.gob.cl/ wp-content/uploads/2018/03/TURISMO-SUSTENTABLE-EN-AP.pdf. 
TAFF, D., NEWMAN, P., LAWSON, S.R., BRIGHT, A., MARIN, L., GIBSON, A. \& ARCHIE, T. The role of messaging on acceptability of military aircraft sounds in Sequoia National Park. Applied Acoustics, 2014, Vol. 84, p. 122-128. https://doi.org/10.1016/j.apacoust.2013.09.012.

TORIGOE, K. A study of the World Soundscape Project. Toronto, CA: York University, 1982.

TRUAX, B. Soundscape studies: An introduction to the World Soundscape Project. Numus West, 1974, Vol. 5, p. 36-39.

TRUAX, B. Acoustic sustainability in urban design: lessons from the World Soundscape Project. Cities \& Health, 2019. https://doi.org/10.1080/23748834.2019.1585133.

ULRICH, R.S., SIMONS, R.F., LOSITO, B.D., FIORITO, E., MILES, M.A. \& ZELSON, M. Stress recovery during exposure to natural and urban environments. Journal of Environmental Psychology, 1991, Vol. 11, p. 201-230.

UNITED STATES NATIONAL PARK SERVICE (USNPS). Management of National Park Service Programs. Washington DC: U.S. Government Printing Office, 2006.

VITTERS $\varnothing$, J., CHIPENIUK, R., SKÅR, M. \& VISTAD, O.I. Recreational conflict is affective: The case of cross-country skiers and snowmobiles. Leisure Sciences, 2004, Vol. 26, ํ3, p. 227-243. https:// doi.org/10.1080/01490400490461378.

WEINZIMMER, D., NEWMAN, P., TAFF, D., BENFIELD, J., LYNCH, E. \& BELL, P. Human Responses to Simulated Motorized Noise in National Parks. Leisure Sciences, 2014, Vol. 36, N³, p. 251-267. https://doi.org/10.1080/01490400.2014.888022.

WHITING, J.W., LARSON, L.R., GREEN, G.T. \& KRALOWEC, C. Outdoor recreation motivation and site preferences across diverse racial/ethnic groups: A case study of Georgia state parks. Journal of Outdoor Recreation and Tourism, 2017, Vol. 18, p. 10-21. https://doi.org/10.1016/j.jort.2017.02.001.

WATTS, G.R. \& PHEASANT, R.J. Tranquillity in the Scottish Highlands and Dartmoor National Park - The importance of soundscapes and emotional factors. Applied Acoustics, 2015, Vol. 89, p. 297305. https://doi.org/10.1016/j.apacoust.2014.10.006

WORBOYS, G. L. \& TRZYNA, T. Managing protected areas. En: WORBOYS, G. L.; LOCKWOOD, M.; KOTHARI, A.; FEARY, S. \& PULSFORD, I. (eds.) Protected Area Governance and Management. Canberra; ANU Press, 2015, p. 169-206. 
